\title{
Evaluation of IFN- $\gamma$, Inflammatory Marker and Infectious Etiology as Risk Factors for Coronary Artery Disease
}

\author{
Meher Rizvi ${ }^{1 *}$, Mehvash Haider², Richa Gupta ${ }^{1}$, Mohd Azam ${ }^{1}$, Abida Malik ${ }^{1}$, and M U Rabbani ${ }^{3}$ \\ ${ }^{1}$ Department of Microbiology, JNMC, AMU, Aligarh, India \\ ${ }^{2}$ Department of Microbiology, Hamdard Institute of Medical Sciences and Research, Jamia Hamdard, New Delhi, India \\ ${ }^{3}$ Department of Medicine JNMC, AMU, Aligarh, India
}

\begin{abstract}
Background: We evaluated the role of Chlamydia pneumoniae (C. pneumoniae) and Cytomegalovirus (CMV) infection in coronary artery disease(CAD) patients. Interferon- $\gamma$ (IFN- $\gamma$ ) levels in serum were assessed for ongoing inflammatory activity by these microorganisms.

Materials and Methods: Persistent and chronic infection of C. pneumoniae was assessed by the level of IgA and IgG antibodies as well as 16S rRNA gene of C.pneumoniae. Chronic CMV presence was detected by IgG antibodies. IFN- $\gamma$ levels in serum were analysed by ELISA.

Results: Among the 63 CAD cases, C. pneumoniae IgG antibodies were present in 34(53.97\%;95\% CI: $41.66 \%$ to $66.28 \%)$ cases, C. pneumoniae IgA antibodies were detected in 42(66.67\%; 95\% CI :55.03\% to 78.31\%) cases ( $<<0.05)$. PCR for detection of C. pneumoniae was done on 40 cases, among which 13 (32.5\%; 95\% CI: 17.99\% to 47.01\%) of cases were positive for 16SrRNA gene of C. pneumoniae. CMV IgG was positive in 41 (65.08\%; 95\% CI: $53.31 \%$ to $76.85 \%)$ cases. On assessing the patients of CAD for major traditional risk factors,35(55.55\%) had past history of CAD, 20(31.75\%) of dyslipidemia, $19(30.16 \%)$ gave history of smoking and 18 (28.75\%) were obese. On comparison of infectious etiology and traditional risk factors, it was clear that $\mathrm{C}$. pneumoniae and CMV both were more $(\mathrm{p}<0.001)$ strongly associated with CAD than the traditional risk factors. Mean level of IFN- $\gamma$ in these patients was $32.13 \mathrm{pg} / \mathrm{ml}$ and that of controls was $11.32 \mathrm{pg} / \mathrm{ml}$. Raised IFN- $\gamma$ was observed in 39 (61.9\%) patients of which 14 (35.9\%) were patients of primary hypertension, 7 (17.9\%) were patients of angina and $18(46.15 \%)$ were patients of MI.
\end{abstract}

Conclusions: C. pneumoniae and chronic CMV infection appear to have a role in the pathogenesis of CAD. Elevated IFN- $\gamma$ levels suggests that these pathogens aggravate the inflammatory process of atherogenesis and hasten the disease process.

Keywords: Coronary Artery Disease, Chlamydia Pneumoniae, CMV, IFN- $\gamma$

\section{Introduction}

Coronary artery disease (CAD) is a major cause of morbidity and mortality worldwide. Asian Indians are reported to have three times higher rates of incidence and prevalence of CAD when compared with western populations, ${ }^{[1,2]}$ leading to a greater social and economic impact. ${ }^{[3,4]}$ Various factors, such as metabolic syndrome, diabetes, dyslipidemia and possible genetic predisposition are believed to contribute to this rising epidemic in India. [1] The known risk factors of CAD are not sufficient to explain all the epidemiological variables and fluctuations of the disease. These observations have fueled renewed interest in the link between CAD and infectious agents. The hypothesis of infectious etiology of atherosclerosis is one of the most interesting areas of vascular research, it states that more than one infectious agent could play a role in atherogenesis and atherothrombosis. This entire process may involve pro-inflammatory mechanisms like interleukins and cytokines. ${ }^{[5]}$ Infectious agents are considered as significant factors in the pathogenesis of atherosclerosis because atherogenic processes resemble chronic inflammation-a process that may be promoted by microorganisms like Chlamydia pneumoniae (C. pneumoniae) and Cytomegalovirus (CMV). The hypothesis of infectious etiology is very attractive because it would provide us with a powerful platform for prevention and treatment of a disease which represents an escalating public health problem worldwide and even more so in India. Even after extensive research the role of infectious agents in CAD still remains an enigma. ${ }^{[5]}$

Till date the question of whether C. pneumoniae and CMV have a direct role in CAD or are innocent bystanders remains unresolved but it continues to be an ever intriguing possibility. If a temporal or casual relationship is established between $C$. pneumoniae and CMV with CAD it would bracket CAD in the rare category of "Preventable Chronic Diseases" - where a simple antibiotic or antiviral may go a long way in preventing this disease. The impact 
on public health and preventive medicine in terms of mortality, morbidity, cost effectiveness and reduction in interventional cardiology procedures will be dramatic. Both C. pneumoniae and CMV are intracellular pathogens, we felt that IFN- $\gamma$ would be the first key cytokine to rise that could in turn activate the chain of events that could unleash a "cytokine-storm" causing a worsening of atherogenesis. In chronic diseases such as in CAD, biochemical reactions induced by IFN- $\gamma$ may have detrimental consequences for host cells. Therefore, the aim of this study was to study the prevalence and association of $C$. pneumoniae and Cytomegalovirus with CAD and evaluation of inflammatory marker (IFN- $\gamma$ ) as potential predictors of risk for cardiovascular events.

\section{Materials and Methods}

A prospective study was conducted at the Departments of Microbiology and Medicine, Jawaharlal Nehru Medical College, AMU, Aligarh, from November 2008 to September 2009.Study group consisted of 63 randomly selected patients with CAD.A written and informed consent was obtained from all subjects. Ethical clearance was obtained by ethical committee of JNMC. Control arm consisted of 30 age and sex matched healthy volunteers. Controls were confirmed for absence of disease by measurement of blood pressure and relevant investigations. The controls were non-hypertensive, non-diabetic and non-smokers. The study approach was: persistent and chronic infection of C. pneumoniae was assessed by the level of IgA and IgG antibodies to $C$. pneumoniae respectively; acute infection of $C$. pneumoniae was assessed by the detection of the 16SrRNA gene of C. pneumoniae, and the chronic CMV infection was detected by level of IgG antibodies. The level of IFN- $\gamma$ in serum was used to assess inflammatory activity.

We included only patients with CAD.CAD is defined as a progressive reduction in blood flow to the myocardium due to the buildup of atheromatous plaques. It manifests as stable angina, unstable angina and myocardial infarction (MI). Unstable angina is defined as one of the following in presence of chest pain occurring at rest that lasts for longer than 10 minutes, or chest pain of severe and new onset(within the prior four to six weeks),or chest pain occurring with a crescendo pattern(more severe and more frequent). Stable angina is defined as chest pain which begins slowly and gets worse with physical activity and is relieved on medication or rest. Myocardial infarction is defined as chest pain lasting more than 30 minutes with ST segment elevation/ depression, evolving Q waves, symmetric inversion of $\mathrm{T}$ waves and elevation of cardiac markers. Patients were confirmed as having coronary artery disease by testing for cardiac injury markers such as creatinine phosphokinase, Troponin-T, Troponin-I, coronary angiography and stress testing. Exclusion criteria were as follows: patients with secondary hypertension (renal causes, endocrine causes, drug induced); patients with pulmonary involvement (e.g. chronic obstructive pulmonary disease [COPD], pneumonia, etc.) or with any other septic foci; and patients with history of antibiotic intake in the previous one month.

After obtaining informed consent, a detailed clinical history and medical examination was performed. Blood pressure was measured for all subjects in a quiet room using a sphygmomanometer and according to standard methods. A blood pressure reading higher than 140/90mm $\mathrm{Hg}$ on two or more occasions measured at least eight hours apart was considered as hypertension.

A sample of venous blood was also collected from each subject in the study after a 10-hour overnight fast for determination of their fasting total cholesterol and blood sugar using the enzymatic colorimetric method. Hypercholesterolemia was defined as a total cholesterol level of $\geq 6.2 \mathrm{mmol} / \mathrm{L}$. Blood sugar estimation was also performed in all patients and non-diabetic subjects were given $75 \mathrm{~g}$ of glucose after an overnight fast for an oral glucose tolerance test. A case of diabetes mellitus was defined as a subject with a known history or with a twohour plasma glucose concentration $\geq 11.1 \mathrm{mmol} / \mathrm{L}$ by the oral glucose tolerance test. Electrocardiograph (ECG) was performed in all cases.

Collection of Sample for Serology and Amplification of $16 \operatorname{SrRNA}$ : Taking all aseptic precautions, $10 \mathrm{ml}$ blood was obtained by venipuncture, $5 \mathrm{ml}$ in an EDTA vial and $5 \mathrm{ml}$ in plain vial. Serum was separated from the samples in a plain vials by centrifugation and stored at $-20^{\circ} \mathrm{C}$. Samples in the EDTA vials were used for DNA extraction by the phenol chloroform extraction method.

Serology : IgA antibodies to C. pneumoniae were detected by Sero $\mathrm{CP}^{\mathrm{TM}} \operatorname{IgA}$ (Savyon Diagnostics, St. Ashdod, Israel). IgG antibodies to $C$. pneumoniae was detected by sero $\mathrm{CP}^{\mathrm{TM}} \mathrm{IgG}$ obtained from SAVYON DIAGNOSTICS, Israel. IgG antibodies to Cytomegalovirus were detected by kit obtained from Calbiotech Diagnostics, USA. The human IFN- $\gamma$ ELISA was used for the in-vitro quantitative determination of interferon gamma (IFN- $\gamma$ ) in human serum. The kit was obtained from Diaclone, Stamford, Connecticut, USA.

Amplification : PCR for detection of the 16SrRNA gene of $C$. pneumoniae was performed for 40 cases and 11 controls. Primers were ordered from Fermentas, Life Sciences, Maryland, USA. The sequences for primer 
pairs of 16SrRNA were as follows: 5' GCT GGC GGC GTG GAT G 3' 832 bp 5' CGA CAC GGA TGG GGT TG 3' using Master Mix from Fermentas, Life sciences, Maryland USA.

Statistical Analysis : The data were entered and analyzed using the Statistical Package for the Social Sciences version 17.0 (SPSS, Chicago, USA).Continuous variables were presented using mean \pm standard deviation while categorical variables were presented as proportions. Categorical comparisons were made using Chi-square/ Kruskal-Wallis test where appropriate and a $P$ value of less than 0.05 was considered significant.

\section{Result}

Among the 63 CAD cases, highest number of patients [29(44.4\%)] were of MI followed closely by primary hypertension (HTN) 21(33.3\%) and angina 14(22\%) (Table 1).Males 38(60\%) outnumbered females $25(40 \%)$. No difference was found in hypertensives, but males were significantly more in angina patients $(\mathrm{p}<0.01)$ and MI patients $(\mathrm{p}<0.05)$. The mean age distribution was $52.7 \pm$ 8.9 years in cases and $54.01 \pm 8.1$ years in controls.

While C. pneumoniae $\operatorname{IgG}$ antibodies were detected in $34(53.97 \%$; $95 \% \mathrm{CI}: \pm 12.31$, range $41.66 \%-66.28 \%$ ) cases, C. pneumoniae IgA antibodies were detected in a larger no. $42(66.67 \% ; 95 \%$ CI : \pm 11.64 , range $55.03 \%-78.31 \%)$ cases( $<0.05) . P C R$ for detection of $C$. pneumoniae was done on 40 cases and 11 controls.13 (32.5\%;95\% CI: \pm 14.51 ,range $17.99 \%-47.01 \%$ ) of cases were positive for $16 \mathrm{~S}$ rRNA gene of $C$ pneumoniae. None of the controls were positive. CMV IgG was detected in 41(65.08\%;95\% CI: \pm 11.71 , range $53.31 \%-76.85 \%$ ) cases.

On comparing C. pneumoniae IgA and IgG seropositivity, it was observed that $\operatorname{IgA}$ antibodies were seen in a larger percentage of patients with MI (71.43\%) and $\mathrm{HTN}(61.9 \%)$ as compared to $\operatorname{IgG}$ prevalence in $\operatorname{MI}(53.47 \%)$ and HTN(42.5\%).However C. pneumoniae IgG antibodies predominated in patients with angina $(71.43 \%)$ as compared to $\operatorname{IgA}(64.29 \%)$ (Table1). The sensitivity (Sn), specificity (Sp), positive predictive value (PPV), negative predictive value (NPV) and odds ratio (OR) for serological tests are depicted in Table 2.

C. pneumoniae IgA antibodies were detected in $42(66.66 \%)$ cases and $12(41.37 \%)$ controls. This test had a $\mathrm{Sn}$ of $66.66 \%$, Sp of $51.72 \%$, PPVof $63.63 \%$, NPVof $41.67 \%$ and OR of 2:14. Association of C. pneumoniae IgA with CVD was statistically significant $(\mathrm{p}<0.05)$. Among these angina patients had higher sensitivity $(64.29 \%)$ and NPV (77.27\%), whereas MI cases had higher PPV (56.25\%) and an odds ratio of 3.54 .
C. pneumoniae $\operatorname{IgG}$ antibodies were detected in $34(53.97 \%)$ cases and $14(48.28 \%)$ controls. This test had a Sn of $53.97 \%$, Sp of $51.72 \%$, PPV of $70.83 \%$, NPV of $31.09 \%$ and an OR of 1.26 . However the rate of positivity in cases and controls was statistically not significant. Among C. pneumoniae IgG seropositives, MI patients had higher Sn (53.57\%) and PPV (51.72\%), however angina patients showed higher NPV (78.95\%) and an OR of 2.86. Out of 63 cases 41(65.08\%) were positive for IgG antibodies against $\mathrm{CMV}$ and $8(27.58 \%)$ of the controls were $\operatorname{IgG}$ positive $(\mathrm{p}<0.01)$. Sn of this test was $65.08 \%$, Sp was $72.41 \%$, PPV (83.67\%), NPV (48.84\%), and an OR of 4.89. Among CMV IgG seropositives, MI patients showed higher Sn (67.86\%),PPV(70.37\%) and OR(5.54) whereas higher $\operatorname{NPV}(80.77 \%)$ was observed in angina patients.

High OR associated with $C$. pneumoniae $\operatorname{IgA}$ antibodies in patients of $\mathrm{CAD}$ suggests their role in its pathogenesis. Infact OR was highest in MI (3.54) and lowest in hypertensive (2.3) patients which is again pointing to a spectrum of diseases. Similar association was observed in CMV, however OR were far higher in all three disease groups, especially so in MI patients (5.54).

16 SrRNA Gene of C. Pneumoniae: PCR for detection of $C$. pneumoniae was performed for 40 cases (15 of MI $\&$ HTN each and 10 of angina) and 11 controls. Thirteen (32.5\%) of the cases and none of the controls were positive on PCR. $6(40 \%)$ of 15 hypertensives 5(33.3\%) of 15 patients of MI and 2(20\%) of 10 angina patients were PCR positive. Among 13 PCR positive cases, majority 10(38.46\%) demonstrated C. pneumoniae IgA antibodies and only $5(23.81 \%)$ were positive for $C$. pneumoniae IgG (Figure 1).

\section{Assessment of Infection and Traditional Risk Factors for} Development of CAD: On assessing the patients of CAD for major traditional risk factors, $35(55.55 \%)$ had past history of CAD, 20 (31.75\%) of dyslipidemia,19 (30.16\%) gave history of smoking and $18(28.75 \%)$ were obese.

On comparison of infectious etiology (as putative risk factors) and traditional risk factors, it was clear that $C$. pneumoniae and CMV both were more $(p<0.001)$ strongly associated with $\mathrm{CAD}$ than the traditional risk factors (Table 3).

Estimation of Interferon- $\gamma($ IFN- $\gamma$ ) Levels: IFN- $\gamma$ was raised in most of the patients with CVD. The mean level of IFN- $\gamma$ in these patients was $32.13 \mathrm{pg} / \mathrm{ml}$ and that of controls was $11.32 \mathrm{pg} / \mathrm{ml}$. Raised IFN- $\gamma$ was observed in $39(61.9 \%)$ patients of which $14(35.9 \%)$ were patients of primary hypertension,7(17.9\%) were patients of angina and 18 
$(46.15 \%)$ were patients of MI. The mean level of IFN- $\gamma$ in hypertensives was $3.39 \mathrm{pg} / \mathrm{ml}$, in patients of angina was $18.5 \mathrm{pg} / \mathrm{ml}$ and on MI patients was $23.89 \mathrm{pg} / \mathrm{ml}$. Of these, 30 (76.92\%) were C. pneumoniae IgA seropositive,
$27(69.23 \%)$ were C. pneumoniae IgG seropositive and 26(66.7\%) CMV IgG seropositive. Correlation of Interferon- $\gamma$ with $C$. pneumoniae and Cytomegalovirus seropositivity in different study groups is given in Figure 2.

Table 1: Prevalence of C. pneumoniae and CMV in different disease groups

\begin{tabular}{|l|c|c|c|c|}
\hline $\begin{array}{l}\text { STUDY GROUP } \\
\mathrm{n}=63\end{array}$ & $\begin{array}{c}\text { C. pneumoniae IgG } \\
\mathrm{n}=34\end{array}$ & $\begin{array}{c}\text { C. pneumoniae IgA } \\
\mathrm{n=42}\end{array}$ & $\begin{array}{c}\text { C. pneumoniae } \\
\text { PCR positivity } \\
\mathrm{n}=13\end{array}$ & $\begin{array}{c}\text { Cytomegalovirus } \\
\text { IgG } \mathrm{n=41}\end{array}$ \\
\hline $\begin{array}{l}\text { Primary Hypertension } \\
\mathrm{n}=21\end{array}$ & $9(42.85 \%)$ & $13(61.90 \%)$ & $6(40 \%)$ & $13(61.90 \%)$ \\
\hline Angina $\mathrm{n}=14$ & $10(71.43 \%)$ & $9(64.29 \%)$ & $2(20 \%)$ & $9(64.29 \%)$ \\
\hline Myocardial Infarction $\mathrm{n}=28$ & $15(53.57 \%)$ & $20(71.43 \%)$ & $5(33 \%)$ & $19(67.86 \%)$ \\
\hline CONTROLS $n=29$ & $14(48.27 \%)$ & $12(41.37 \%)$ & 0 & $8(27.5 \%)$ \\
\hline
\end{tabular}

Table 2: Comparison of performance of different serological tests used. (Cases=63, Controls=30)

\begin{tabular}{|c|c|c|c|c|c|}
\hline Serology & Sensitivity & Specificity & $\begin{array}{c}\text { Positive } \\
\text { Predictive value }\end{array}$ & $\begin{array}{c}\text { Negative } \\
\text { Predictive value }\end{array}$ & Odds ratio \\
\hline C.pn IgG & $53.97 \%$ & $51.72 \%$ & $70.83 \%$ & $31.09 \%$ & 1.26 \\
\hline HTN & $42.86 \%$ & $51.72 \%$ & $39.13 \%$ & $55.55 \%$ & 0.80 \\
\hline Ang & $71.43 \%$ & $51.72 \%$ & $41.66 \%$ & $78.95 \%$ & 2.86 \\
\hline MI & $53.57 \%$ & $51.72 \%$ & $51.72 \%$ & $53.57 \%$ & 1.24 \\
\hline C. pn $\lg A$ & $66.6 \%$ & $58.62 \%$ & $63.63 \%$ & $41.67 \%$ & 2.14 \\
\hline HTN & $61.9 \%$ & $58.62 \%$ & $52 \%$ & $68 \%$ & 2.3 \\
\hline Ang & $64.29 \%$ & $58.62 \%$ & $42.86 \%$ & $77.27 \%$ & 2.55 \\
\hline $\mathrm{Ml}$ & $71.43 \%$ & $58.62 \%$ & $56.25 \%$ & $68 \%$ & 3.54 \\
\hline CMV IgG & $65.08 \%$ & $72.41 \%$ & $83.67 \%$ & $48.84 \%$ & 4.89 \\
\hline HTN & $61.90 \%$ & $72.41 \%$ & $61.90 \%$ & $72.41 \%$ & 4.27 \\
\hline
\end{tabular}

Table 3: Evaluation of traditional risk factors and C. pneumoniae \& CMV infection as risk factor in CAD.

\begin{tabular}{|l|c|}
\hline Risk Factors & \multicolumn{2}{|c|}{ Positive Cases n=63 } \\
\hline Traditional Risk Factors & $5(7.94 \%)$ \\
\hline Smoking & $20(31.75 \%)$ \\
\hline Diabetes & $18(28.75 \%)$ \\
\hline Dyslipidemia & $12(19.05)$ \\
\hline Obesity & $35(55.55)$ \\
\hline Family History & \\
\hline Past History & $42(66.66)$ \\
\hline Infectious Etiology as Risk Factor & \\
\hline C.pneumoniae IgA & \\
\hline
\end{tabular}




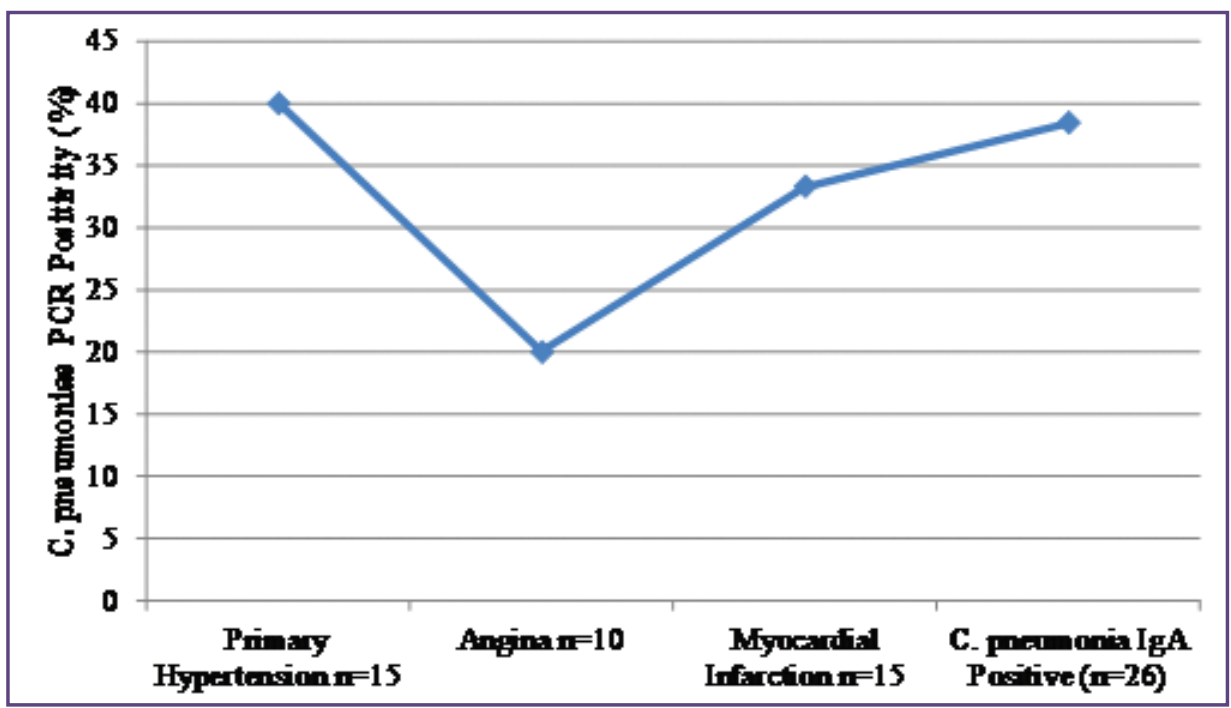

Fig. 1: C. pneumoniae PCR positivity according to study Group and seropositivity $(n=13)$

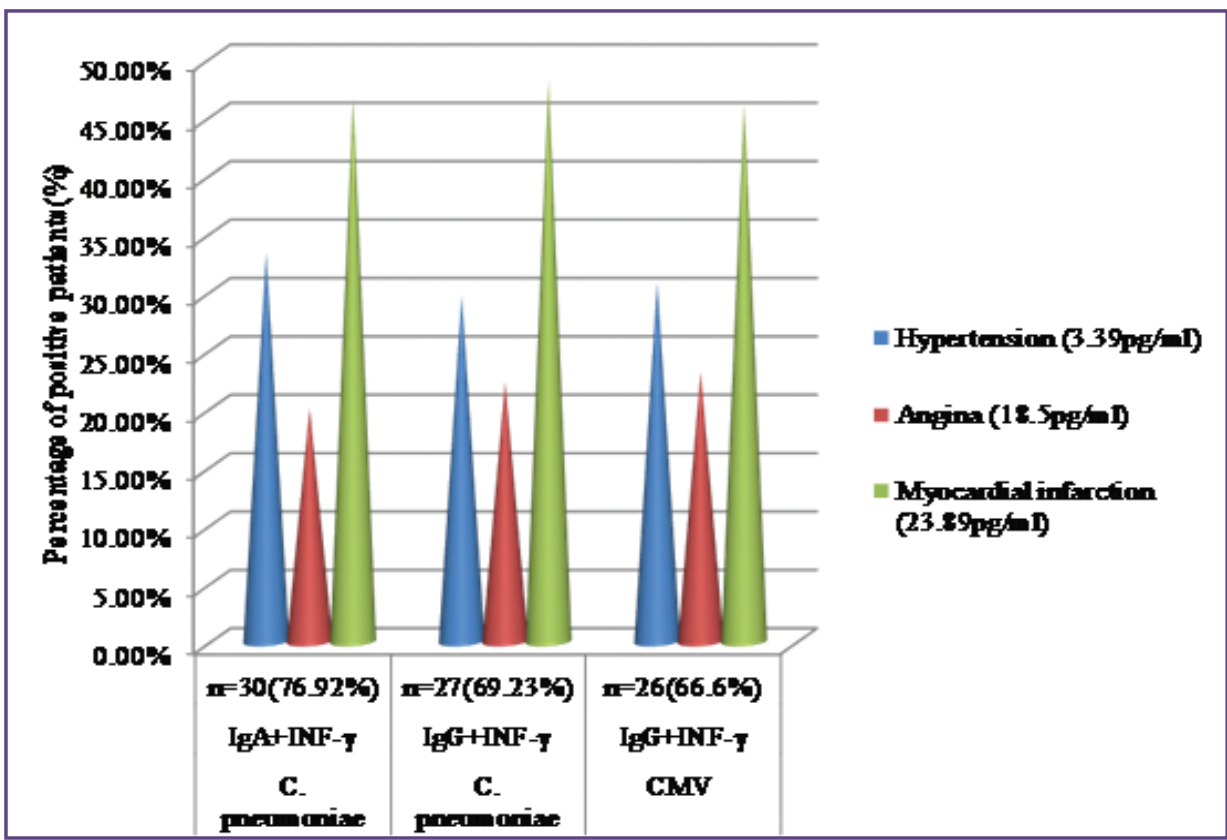

Fig. 2: Correlation of Interferon- $\gamma$ with Chlamydia pneumonia and cytomegalovirus seropositivity in different study groups

\section{Discussion}

Chlamydia pneumoniae. C. pneumoniae is a gramnegative intracellular bacterium. An association of coronary heart disease and infections with C. pneumoniae, an important respiratory pathogen, has been initially found by sero-epidemiologic studies. The presence of $C$. pneumoniae has been shown in atheromatous plaques of coronary and carotid arteries ${ }^{[6,7,8]}$. An immune reaction to chlamydial Hsp60 has been shown in coronary atheroma tissue, especially in macrophages and foam cells ${ }^{[9]}$. In human carotid artery plaques, $C$. pneumoniae reactive T lymphocytes have been identified ${ }^{[10]}$. A further possible role of $C$. pneumoniae in the pathogenesis of arteriosclerosis could be that chronic or acute chlamydial infection anywhere in the body activates arteriosclerotic plaques. An association between immunoglobulin A (IgA), but not IgG, antibodies to C. pneumoniae and the subsequent risk of death from ischemic heart disease, the risk of ischemic 
stroke, and the severity of arteriosclerosis of carotid or femoral arteries has been found ${ }^{[11]}$. In patients undergoing carotid endarterectomy, the plaques were investigated for C.pneumoniae and the blood was examined for antichlamydial antibodies. Associated with symptomatic disease was a high level of antichlamydial IgA, whereas no association between $C$. pneumoniae presence in the plaque and symptomatic disease could be detected ${ }^{[12]}$. Furthermore, there are indications that seropositivity for C. pneumoniae might enhance the atherogenic effects of other vascular injuries. A case-control study suggests that the proatherogenic effects of lipoprotein may be enhanced or partly mediated through the formation of circulating immune complexes containing C. pneumoniae specific IgG antibodies ${ }^{[13]}$. The simultaneous presence of high levels of antibodies to $C$. pneumoniae and of antibodies to human Hsp60 have been found to substantially increase the risk for coronary arteriosclerosis ${ }^{[14]}$.

Cytomegalovirus (CMV): CMV infection of endothelial cells may increase cellular proliferation and inhibit apoptosis of infected smooth-muscle cells, thereby contributing to an increase in the mass of arteriosclerotic lesions. Furthermore, individuals infected with CMV have impaired endothelium- mediated coronary vasodilator responses ${ }^{[15]}$. Two studies in patients undergoing coronary angiography have shown that CMV elicits a subclinical inflammatory response, but only in certain individuals, and that individuals with an inflammatory response appear to be susceptible to the atherogenic effects of CMV, whereas those without such a response appear to be resistant ${ }^{[16,17]}$. Postulating that sex might have an effect on patterns of inflammatory and immune responses to CMV infection, a study in patients evaluated for coronary artery disease found that, in men, CMV appears to contribute to coronary artery disease risk, in so far as it predisposes to inflammation. In women, other mechanisms, possibly related to the type of immune response generated by the host, appear to be responsible for the proatherogenic effects of $\mathrm{CMV}^{[18]}$.

Recently, total number of deaths due to CAD has increased globally to 17.5 million from 14.4 million in 1990. More than 80 percent of the deaths occurred in low and middle income countries. ${ }^{[19,20,21]}$ WHO estimates there will be about 20 million CAD deaths in 2015, accounting for 30 percent of all deaths worldwide. ${ }^{[22]}$ There are well known risk factors for $\mathrm{CAD}$ such as hypertension, diabetes mellitus and obesity. ${ }^{[23]}$ However in approxiamately $50 \%$ cases of CAD no identifiable risk factors are observed. ${ }^{24]}$ Consequently, despite advances in the pharmacological control of hypertension and diabetes, as well as mounting efforts in discouraging smoking, the decrease in the clinical complications of atherosclerosis has been modest, indicating that there are as yet unknown contributory factors in the pathogenesis of atherosclerosis. This has spurred passionate search for new risk factors such as infectious agents, inflammatory markers and coagulation factors. ${ }^{[25]}$ In a study from India, C. pneumoniae was detected in $73.7 \%$ of CAD patients. ${ }^{[26]}$

In this we study we assessed the role of $C$. pneumoniae and CMV in pathogenesis of CAD. C. pneumoniae IgA antibodies were detected in $42(66.66 \%)$ cases and 12 $(41.37 \%)$ controls. Primary C. pneumoniae infection is characterized by a significant immunoglobulin (IgM) antibody response, a delayed IgG titer and a low IgA level. Secondary infection with C. pneumoniae infection is notable for an absence of IgM antibody and elevated IgA and IgG levels. ${ }^{[27]}$ It has been suggested that serum IgA antibody titers to $C$. pneumoniae may be more predictive of coronary heart disease than are IgG titres because IgA antibodies have different biological characteristics(such as shorter half- life) and may be better indicators of persistent chlamydial infection in certain chronic diseases. ${ }^{[28]}$ This test had a Sn of $66.66 \%$,Sp of $51.72 \%$, PPV of $63.63 \%$,NPVof $41.67 \%$ and an OR of 2:14.Detection of C. pneumoniae in CAD cases was statistically significant $(p<0.05)$.A few small studies have reported stronger associations of $C$. pneumoniae IgA titers with MI ${ }^{[29]}$ or stroke. ${ }^{[28]}$

C. pneumoniae $\mathrm{IgG}$ antibodies were detected in a lower no. of 34(53.97\%) cases and 14(48.28\%) controls. This test had a Sn of $53.97 \%$,Sp of $51.72 \%$,PPVof $70.83 \%$,NPVof $31.09 \%$ and an OR of 1.26 . However the rate of positivity in cases and controls was statistically not significant. Maximum IgG seropositives 15 (53.57\%) were among MI patients followed by $10(71.43 \%)$ angina patients and $9(42.85 \%)$ in hypertensives. No statistical difference was found on comparing seropositivity in different study groups within themselves and with healthy controls. Our findings are in contrast to another study where the investigators showed that cases had a higher frequency of IgG seropositivity than did non cases. ${ }^{[29]}$ However another study showed no evidence of association between $C$. pneumoniae IgG seropositivity and risks of future MI. ${ }^{[30]}$

A great majority of cross-sectional and retrospective studies suggest that a positive association for $C$. pneumoniae have relied primarily or exclusively on serology to determine exposure status. ${ }^{[31]}$ Previous studies have used the presence of $\operatorname{IgG}$ and $\operatorname{IgA}$ antibody to $C$. pneumoniae as a proxy for chronic infection, but the validity of this approach is uncertain. C. pneumoniae infection generally starts in the respiratory tract and probably disseminates systemically in the blood stream within alveolar macrophages. In both laboratory animals and human subjects, the persistence of 
vascular C. pneumoniae DNA has been associated with the presence of viable organism. ${ }^{[32]}$ We therefore assessed the prevalence of $C$. pneumoniae DNA in the blood mononuclear cells of 40 patients of CVD and correlated the results with clinical and other parameters. PCR for detection of $C$. pneumoniae was done on 40 cases and 11 controls. $13(32.5 \%)$ cases were positive by PCR $(p<0.05)$. None of the controls were positive. Boman et al, working in Sweden first demonstrated the detection of $C$. pneumoniae DNA in PMBC of cardiac patients. ${ }^{[33]}$ They found a prevalence of $C$. pneumoniae $59 \%$ in patients. The largest of these nine studies examined 1,205 British patients undergoing coronary angiography and was conducted by Wong et al. ${ }^{[34]}$ They found a low prevalence of $8.7 \%$ in patients with angiographic ally proven $\mathrm{CAD}$, versus $7.2 \%$ in those with normal coronary arteries. There is limited epidemiological evidence relating CMV specifically to primary coronary atheroma in immune-competent individuals. ${ }^{[35]}$

Out of 63 cases $41(65.08 \%)$ were positive for $\operatorname{IgG}$ antibodies against $\mathrm{CMV}$ and $8(27.58 \%)$ of 29 controls were IgG positive. Detection of CMV was significantly more $(p<0.01)$ in cases than controls. Sn of this test was $65.08 \%$, Sp was $72.41 \%, \operatorname{PPV}(83.67 \%), \mathrm{NPV}(48.84 \%)$ and an OR of 4.89.Among CMV IgG seropositives, MI patients showed higher Sn (67.86\%),PPV(70.37\%) and OR(5.54) whereas higher NPV $(80.77 \%)$ was observed in angina patients. The results of a study by Grayston JT et al ${ }^{[36]}$ demonstrated a similar prevalence of seropositivity in patients with coronary artery disease and in an age and sex matched control group; however, anti-CMV IgG antibody titers were higher in patients with coronary artery disease ( $52 \%$ of the patients had $\geq 1: 800$ anti-CMV titres, whereas only $16 \%$ of the control group had high antibody titers).

A quantitative analysis if IFN- $\gamma$ levels in CVD patients was done using ELISA.A total of 39 patients were assessed, out of which $38.9 \%$ were primary hypertensives, $17.95 \%$ were angina patients and majority 43.59 were MI patients. Most of these patients were C. pneumoniae or CMV serology positive. The mean value of IFN- $\gamma$ in CAD cases was $15.3 \pm 51.2 \mathrm{pg} / \mathrm{ml}$. The mean value of IFN- $\gamma$ in hypertensives was $3.39 \mathrm{pg} / \mathrm{ml}$, of Angina patients was $18.5 \mathrm{pg} / \mathrm{ml}$ and of MI patients was $23.89 \mathrm{pg} / \mathrm{ml}$. The mean of controls was $5.15 \pm 4.16 \mathrm{pg} / \mathrm{ml}$. A study found that mononuclear leukocytes from patients with stable as well as unstable angina pectoris secrete significantly more IFN- $\gamma$ and TNF- $\alpha$ than do the mononuclear cells from healthy but elderly control subjects. ${ }^{[37,38]}$ An interesting trend of increasing value of IFN- $\gamma$ with the severity and chronicity of CVD is clearly visible in our study. This may suggest an increasing role of inflammation and inflammatory markers not only in the initiation but also in the progression of
CVD. But in contrast to our study, Hem C.J. reported IFN- $\gamma$ was significantly lower $(\mathrm{P}=0.006)$ in $C$. pneumoniae IgA negative patients. ${ }^{[39,40,41]}$

Although there were $30(76.92 \%)$ patients who had $C$. pneumoniae IgA and IFN- $\gamma$ elevated and $27(69.23 \%)$ patients who had $C$. pneumoniae IgG and IFN- $\gamma$ elevated there was considerable overlapping, so there were actually only $22(56.41 \%$ ) patients had C. pneumoniae $\operatorname{IgA}$ and $\operatorname{IgG}$ with IFN- $\gamma$ elevated. Only $15(38.46 \%)$ patients had $C$. pneumoniae IgA, IgG and CMV IgG elevated with IFN- $\gamma$. So contrary to our expectation number of patients coinfected with C. pneumoniae and CMV with raised IFN- $\gamma$ were not more. Thus we re-evaluated our understanding of the inflammatory potential of C.pneumoniae. Patients positive for $C$. pneumoniae IgA were more susceptible to elevated Th1 response due to increased levels of IFN- $\gamma$. We hypothesize that such patients (C. pneumoniae IgA positive with raised IFN- $\gamma$ ) risk of adverse clinical outcome.

\section{Conclusion}

In this study C. pneumoniae and CMV both appear to have a role in pathogenesis of CAD. However it would be more sapient to take them as added risk factors in causation of CAD. In fact compared to traditional risk factors, $C$. pneumoniae and CMV were more significant risk factors in the present study. Moreover, their potential to trigger an inflammatory response superimposed on the natural atherogenetic process may hasten the pathogenesis of CAD. On analyzing association of infection with IFN- $\gamma$, we observed that persistent infection with raised interferon correlated well with chronicity and severity of disease. Large scale prospective studies with longer follow-up and confirmation of disease status by imaging techniques like angiography are needed to further elucidate the role of these agents. If their role is proven without doubt then we would have in our hands a "major modifiable risk factor". This would radically change the way we prevent and treat cardiovascular diseases. A window for research for similar "modifiable risk factors" in other chronic diseases will also be thrown open.

\section{Acknowledgements}

Thanks to Mohd Azam for helping in the molecular work.

\section{References}

1. Enas EA, Singh V, Munjal YP. Reducing the burden of coronary artery disease in India: Challenges and opportunities. Indian Heart J 2008;60:161-75.

2. Hansa G, Bhargava K, Bansal M, Tandon S, Kasliwal RR. Carotid intima-media thickness and coronary artery disease: An Indian perspective. Asian Cardiovasc Thorac Ann 2003;11:217-21. 
3. Goyal P, Kalek SC, Chaudhry R, Chauhan S, Shah N. Association of common chronic infections with coronary artery disease in patients without any conventional risk factors. Indian J Med Res 2007;125:129-36.

4. Gupta R. Secondary prevention of coronary artery disease in urban Indian primary care. Int J Cardiol 2009;135:184-6.

5. Gayelos CA, Quinn TC. The role of Chlamydia pneumoniae in cardiovascular disease. Adv Intern Med 2000; 45:139-73.

6. Saikku P, Leinonen M, Mattila K, Ekman MR, Nieminen MS, Mäkelä PH, Huttunen JK, Valtonen V. Serological evidence of an association of a novel Chlamydia, TWAR, with chronic coronary heart disease and acute myocardial infarction. Lancet.1988; 2:983-986.

7. Yamashita K, Ouchi K, Shirai M, Gondo T, Nakazawa T, Ito H. Distribution of Chlamydia pneumoniae infection in the atherosclerotic carotid artery. Stroke. 1998;29:773-778.

8. Campbell LA., O'Brien ER, Cappuccio AL, et al. Detection of Chlamydia pneumoniae TWAR in human coronary atherectomy tissues.J. Infect. Dis. 1995;172:585-588.

9. Bauriedel G, Andrié R, Likungu J A, Welz A, Braun P, Welsch U, Lüderitz B. Persistenz von Chlamydia pneumoniae in koronarem Plaquegewebe. Ein Beitrag zur Infektions- und Immunhypothese bei instabiler Angina pectoris. Dtsch. Med. Wschr. 1999;124:1408-1413.

10. Mosorin, M., Surcel HM, Laurila A, et al. Detection of Chlamydia pneumoniae-reactive $\mathrm{T}$ lymphocytes in human atherosclerotic plaques of carotid artery. Arterioscler. Thromb. Vasc. Biol.2000;20:1061-1067.

11. Elkind MSV, Lin I F, Grayston J T, Sacco R L. Chlamydia pneumoniae and the risk of first ischemic stroke. The Northern Manhattan Stroke Study. Stroke 2000;31: 1521-1525.

12. LaBiche R, Koziol D, Quinn T C, Gaydos C, Azhar S, Ketron G, Sood S, DeGraba TJ. Presence of Chlamydia pneumoniae in human symptomatic and asymptomatic carotid atherosclerotic plaque. Stroke.2001;32:855-860.

13. Glader CA, Boman J, Saikku P, Stenlund S, Weinehall L, Hallmanns G, Dahlén G H. The proatherogenic properties of lipoproteins may be enhanced through the formation of circulating immune complexes containing Chlamydia pneumoniae-specific IgG antibodies. Eur.Heart J. 2000;21:639-646.

14. Burian, K, Kis D Z, Virok V, Endresz Z, Prohaszka J. Duba K. Berencsi K. Boda L.et al. Independent and joint effects of antibodies to human heat-shock protein 60 and Chlamydia pneumoniae infection in the development of coronary atherosclerosis. Circulation 2001;103:1503-1508.

15. Epstein S E, Zhou Y F, Zhu J. Infection and atherosclerosis. Emerging mechanistic paradigms. Circulation. 1999;100:20-28.

16. Blankenberg S, Rupprecht H J, Bickel C, Espinola-Klein C, Rippin G, Hafner G, Ossendorf M, Steinhagen K, Meyer J. Cytomegalovirus infection with interleukin-6 response predicts cardiac mortality in patients with coronary artery disease. Circulation. 2001;103:2915-2921.
17. Zhu JA, Quyyumi A, Norman JE, Csako G, Epstein SE. Cytomegalovirus in the pathogenesis of atherosclerosis. The role of inflammation as reflected by elevated C-reactive protein levels. J. Am. Coll. Cardiol. 1999;34:1738-1743.

18. Zhu J, Shearer G M, Norman J E, Pinto LA, Marincola F M, Prasad A,et al. Host response to cytomegalovirus infection as a determinant of susceptibility to coronary artery disease. Sex-based differences in inflammation and type of immune response. Circulation. 2000; 102:2491-2496.

19. Adeyi O, Smith O, Robles S. Public policy and the challenge of chronic noncommunicable diseases. Washington, DC: The World Bank; 2007.

20. WHO. The global burden of disease: 2004 update. Geneva: World Health Organization; 2008b.

21. WHO. World health statistics 2009. Geneva: World Health Organization; 2009e.

22. WHO Department of Child and Adolescent Health and Development. The current evidence for the burden of group a streptococcal diseases, Discussion papers on child health. Geneva: World Health Organization; 2005.

23. Goldberg RJ, Burchfiel CM, Benfante R, Chiu D, Reed DM, Yano K. Lifestyle and biologic factors associated with atherosclerotic disease in middle-aged men: 20 year findings from the Honolulu Heart Program. Arch intern med 1995; 155:686-94

24. Braunwald E. Shattuk Lecture- cardiovascular medicine at the turnoff the millennium: triumphs, concerns and oppurtunities. N Eng J Med 1997;337:1360-9

25. Mohan V, Deepa R, Shanthirani S, Premlatha G. Prevalence of coronary artery disease and it's relationship to lipids in a selected population in South India. The Chennai Urban Population Study (CUPS). J Am Coll Cardiol 2001; 38:682-687.

26. Satpathy G, Sharma A, Vaish S. Immunocomb Chlamydia bivalent assay to study Chlamydia species specific antibodies in patients with coronary heart disease. Indian J Med Res 2005; 121: 171-175.

27. Grayston JT, Campbell LA, Kuo CC, Mordhorst $\mathrm{CH}$, Saikku P, Thom DH et al. A new respiratory tract pathogen: Chlamydia pneumoniae strain TWAR. J Infect Dis 1990; 161: 618-25.

28. Elkind MSV, Lin I-F, Grayston JT, Sacco RL. Chlamydia pneumoniae and the risk of first ischemic stroke: the Northern Manhattan Stroke Study. Stroke 2000; 31:1521-5.

29. Roivainen M, Viik-Kajander M, Palosou T, Toivanen P, Leinonen M, Saikku P et al. Infections, inflammation and risk of coronary heart disease. Circulation 2000; 101: 252-8.

30. Javier NF, Aaron RF, Sorlie PD, Grayston JT, Wang SP, Lloyd P. Chlamydia pneumoniae infection and Incident Coronary Heart disease. The Atherosclerosis Risk in Communities Study. Am J Epidemiol 1999;150: 149-56.

31. Ridker PM. Inflammation, infection and cardiovascular risk: How good is the clinical evidence? Circulation 1998; 97: $1671-4$ 
32. Danesh J, Wong Y, Ward M, Muir J. Chronic infection with Helicobacter pylori, Chlamydia pneumoniae, or cytomegalovirus: population-based study of coronary heart disease. Heart 1999;81:245-7.

33. Wong YK, Dawkins K, Ward ME. Detection of Chlamydia pneumoniae DNA circulating in the blood of patients attending for cardiac angiography: premilinary clinical and serological correlates. In : Chlamydial Infections (Stephens RS, Byme GI, Christiansen G et al., eds). International Chlamydial Symposium, San Francisco, USA, 1998; 232-8.

34. Boman J, Soderberg S, Forsberg J, Birgander LS, Allard A, Persson $\mathrm{K}$ et al. High prevalence of Chlamydia pneumoniae DNA in peripheral blood mononuclear cells in patients with cardiovascular disease and in middle-aged blood donors. $J$ Infect Dis 1998;178:274-7.

35. Yuk-ki Wong, Dawkins KD, Ward ME. Circulating Chlamydia pneumoniae DNA as a predictor of Coronary Artery Disease. J Am Coll Cardiol 1999; 34: 1435-9.

36. Danesh J, Collins R, Peto R. Chronic infection and coronary heart disease: is there a link? Lancet 1997; 350:430-6.
37. Grayston JT, Golubjatnikov R, Hagiwara T . Serologic tests for Chlamydia pneumoniae. Pediatr Infect dis $J$ 1993;12:790-1.

38. VanDyke TE, VanWinkelhoff A J. Infection and inflammatory mechanisms," Journal of Clinical Periodontology.2013;40:S1-S7.

39. Yusuf S, Anand S. Deciphering the causes of cardiovascular and other complex diseases in populations: achievements, challenges, opportunities, and approaches.Progress in Cardiovascular Diseases2010;53: 62-67.

40. Vaddi K, Nicolini FA, Mehta P, Mehta JL. Increase secretion of tumour Necrosis Factor- $\alpha$ and Interferon- $\gamma$ by Mononuclear Leukocytes in patients with Ischemic Heart Disease Relevance in Superoxide Anion Generation. Circulation1994; 90:694-99.

41. Hem C J, Srivastava P, Sarkar R, Prasad J, Mittal AS. Association of Plasma Circulatory Markers, Chlamydia pneumoniae, and high sensitive C-Reactive protein in Coronary Artery Disease Patients of India. Mediators of Inflammation, Hindawi Publishing Corporation 2009; Volume 9.

*Corresponding author:

Dr. Meher Rizvi, MD, Associate Professor, Department of Microbiology, JNMC, AMU, Aligarh, India

Phone: +919837160124

Email: rizvimeher@gmail.com 